\title{
Vitamin D status as a synthetic biomarker of health status
}

\author{
Philippe Autier ${ }^{1}$
}

Received: 21 September 2015/ Accepted: 16 December 2015/Published online: 30 December 2015

(C) Springer Science+Business Media New York 2016

A considerable number of ecological, cross-sectional and of observational studies have documented the association between low vitamin D status (assessed by the measurement of serum 25-hydroxyvitamin D concentration $[25(\mathrm{OH}) \mathrm{D}])$ and a greater risk of being diagnosed with a myriad of diseases, including minor ailments and rare conditions [1]. Many have concluded from these non-interventional studies that low vitamin D status could be a cause of ill health, and that maintaining a high 25(OH)D could represent an easy way to prevent diseases and increase life expectancy. But the numerous randomised trials done to date on vitamin $\mathrm{D}$ supplementation did not confirm the health benefits of increased $25(\mathrm{OH}) \mathrm{D}$, even when high doses of supplementation (i.e. $\geq 50 \mu \mathrm{g}$ per day) were used in subjects with low vitamin $\mathrm{D}$ status before randomisation [2]. Large-size randomised trials on vitamin D supplementation are on-going [3, 4]. While awaiting for results of these trials, perhaps the cautious view is to consider that low $25(\mathrm{OH}) \mathrm{D}$ is a consequence and not a cause, of debilitated health.

The prospective study of Skaaby and colleagues published in this issue of the journal provides additional evidence that $25(\mathrm{OH}) \mathrm{D}$ depends on the interplay between personal characteristics (e.g. sex, age) and multiple lifestyle (i.e. adiposity, diet, physical activity, smoking, alcohol drinking) factors that are known determinants of major conditions like cardiovascular, metabolic and cancerous

Philippe Autier

philippe.autier@i-pri.org

1 University of Strathclyde Institute of Global Public Health at iPRI, International Prevention Research Institute, Espace Européen, Building G, Allée Claude Debussy, 69130 Ecully Lyon, France diseases, as well as of life expectancy [5]. Importantly, the study demonstrates that changes in lifestyle over time exert profound influence on the vitamin D status. If in addition, the study had prospectively collected information on chronic disease occurrence, systemic inflammation (e.g. repeated measurements of the hsCRP or of the TNF-alpha), and liver and renal function, it is possible that changes in these conditions might have been associated with changes in $25(\mathrm{OH}) \mathrm{D}$. This later hypothesis, however, needs to be confirmed by prospective studies. Considering that the health status of an individual is the result of complex interactions between personal characteristics, genetic make-up, living place, nutrition and lifestyle, physiological parameters and the presence of subclinical or of overt chronic disease(s) and of treatments, then the Skaaby et al. study lends support to the possibility that the $25(\mathrm{OH}) \mathrm{D}$ could represent a synthetic indicator of the health status of an individual that provides a quantitative information on a vast number of factors that may have positive and negative influences on the health status. This possibility is supported by the observation that of all vitamins and anti-oxidative compounds found in the serum, the $25(\mathrm{OH}) \mathrm{D}$ concentration is probably the most sensitive to changes in health status [6].

If this possibility proves correct and feasible, it would open new perspectives for public health action and medical practice. First, repeated measurements of $25(\mathrm{OH}) \mathrm{D}$ could serve for monitoring health status and evaluate the impact of efforts deployed for improving it like the adoption of healthier lifestyle or the successful management of a chronic condition. Conversely, changes in $25(\mathrm{OH}) \mathrm{D}$ may inform on how badly disease occurrence or unwelcome changes in lifestyle have altered the health status.

A second perspective is about individuals found with low $25(\mathrm{OH}) \mathrm{D}$. The usual reaction is to prescribe vitamin $\mathrm{D}$ 
supplementation. However, we know from systematic reviews of randomised trials that vitamin D supplementation does not affect disease occurrence and outcomes [2, 7, 8]. So, according to the new perspective, the first reaction should be to investigate reasons possibly underlying the low status, and if found, to fix them or to mitigate their untoward consequences on health. It follows that successful resolution of reasons involved in low vitamin D status should lead to upward changes in $25(\mathrm{OH}) \mathrm{D}$. Indeed, in this scenario, vitamin D supplementation incapacitates the use of $25(\mathrm{OH}) \mathrm{D}$ for health status monitoring. Therefore, a notable exception for these innovative ways to use 25(OH)D measurements could be groups for which vitamin D supplementation is recommended like pregnant women, small children and frail elderly.

There is, however, a long way to go before $25(\mathrm{OH}) \mathrm{D}$ could be used as a biomarker of health status. For instance, a limitation of the Skaaby et al. study is the absence of an estimation of the total variability in $25(\mathrm{OH}) \mathrm{D}$ during the 5-year period of follow-up, with an estimation of how much of that variability was due to changes in lifestyle. The statistical quantification of changes in $25(\mathrm{OH}) \mathrm{D}$ according to changes in lifestyle or personal factors clearly deserves more research in order to obtain a better appraisal of how well variations in $25(\mathrm{OH}) \mathrm{D}$ over time inform on changes in health determinants. Such quantification could also consider the influence of disease occurrence and changes in physiological parameters known to influence health status and $25(\mathrm{OH}) \mathrm{D}$, like the systemic inflammation, or the liver and renal function. Another aspect will be to determine at which period of the year the measurement of $25(\mathrm{OH}) \mathrm{D}$ offers the most valid information on health status. Most probably the end of the winter season would be the best candidate. It will be also necessary to work on the appropriate way to take care of the influence on $25(\mathrm{OH}) \mathrm{D}$ of casual, recreational or occupational exposures to the sun or to artificial sources of ultraviolet light. Finally, tests for accurate measurement of $25(\mathrm{OH}) \mathrm{D}$ are still costly.

The keen interest of the scientific community for vitamin D status and health expanded rapidly in the 2000s. There is at present growing evidence that increasing the vitamin D status is not a panacea for preventing a multitude of conditions. Studies like the one by Skaaby and colleagues open new and more appropriate avenues for the use of results of huge numbers of $25(\mathrm{OH}) \mathrm{D}$ tests that have become so common in many communities. In this regard, already existing cohort studies could explore whether $25(\mathrm{OH}) \mathrm{D}$ could provide an information to health professionals that would represent a significant addition to knowledge of the smoking status, blood pressure and serum blood lipids.

\section{Compliance with ethical standards}

Conflict of interest None to disclose.

\section{References}

1. N.C. Harvey, C. Cooper, Vitamin D: some perspective please. BMJ 345, e4695 (2012)

2. P. Autier, M. Boniol, C. Pizot, P. Mullie, Vitamin D status and ill health: a systematic review. Lancet Diabetes Endocrinol. 2(1), 76-89 (2014)

3. J.E. Manson, S.S. Bassuk, Vitamin D research and clinical practice: at a crossroads. JAMA 313(13), 1311-1312 (2015)

4. R. Scragg, D. Waayer, A.W. Stewart, C.M. Lawes, L. Toop, J. Murphy, K.T. Khaw, C.A. Camargo Jr., The Vitamin D Assessment (ViDA) Study: design of a randomized controlled trial of vitamin D supplementation for the prevention of cardiovascular disease, acute respiratory infection, falls and nonvertebral fractures. J. Steroid Biochem. Mol. Biol. (2015). doi:10. 1016/j.jsbmb.2015.09.010

5. T. Skaaby, L.L.N. Husemoen, B.H. Thuesen, C. Pisinger, A. Hannemann, T. Jørgensen, A. Linneberg, Longitudinal associations between lifestyle and vitamin D: a general population study with repeated vitamin D measurements. Endocrine (2015). doi:10. 1007/s12020-015-0641-7

6. G. McNeill, J. Vyvyan, H. Peace, L. McKie, G. Seymour, J. Hendry et al., Predictors of micronutrient status in men and women over 75 years old living in the community. Br. J. Nutr. 88(5), 555-561 (2002)

7. M.J. Bolland, A. Grey, G.D. Gamble, I.R. Reid, The effect of vitamin D supplementation on skeletal, vascular, or cancer outcomes: a trial sequential meta-analysis. Lancet Diabetes Endocrinol. 2(4), 307-320 (2014)

8. M.J. Bolland, A. Grey, G.D. Gamble, I.R. Reid, Vitamin D supplementation and falls: a trial sequential meta-analysis. Lancet Diabetes Endocrinol. 2(7), 573-580 (2014) 